\title{
Do we have the power to create our own future as oncology nurses?
}

\author{
By Rose Steele, RN, PhD
}

Dr. Rose Steele is Associate Professor in the School of Nursing at York University in Toronto, Ontario. She was also the Editor-in-Chief of the Canadian Oncology Nursing Journal from 1999 to 2004. This paper was the Keynote Address on Tuesday September 28, 2004, at the sixteenth annual CANO conference in Calgary, Alberta.

It is published here at the request of conference attendees to have Dr. Steele's thoughts shared with all CONJ subscribers.

Good afternoon, everyone. I am delighted to be here at CANO's annual conference in the beautiful city of Calgary. I am especially honoured to be a speaker in CANO's twentieth anniversary year, so thank you for inviting me. It's not easy to follow the previous keynote speakers, you know. I have little sense of musical rhythm, so I won't be using music in my talk, but hopefully I can find my own rhythm and you won't get too bored. And I haven't climbed an actual mountain as Toben Anderson did, though, like many of you I'm sure, I've had my own figurative mountains to climb. Like Toben, I certainly believe in creating the person you want to be and the life you want to live, so that's what I'll share with you today - my thoughts about how nursing got to be where we are and how we might live in the present to create a new future.

Some of you may know me through my work in CANO and particularly as Editor-in-Chief of CONJ, CANO's quarterly peerreviewed journal. But I will share a little more of me with you today to give you a sense of why I am passionate about the role that each of us can play in our own destiny and in the development of our profession. I would encourage you to celebrate our current status as oncology nurses, but I would also challenge you to seize the opportunity to create the future for oncology nursing. Otherwise, someone else will do it for us.

I have been in nursing for 30 years now. I started as a student in a hospital-based program in Scotland back in August of 1974, and earned my RN designation after three calendar years of hard work. Over the years, I added to my basic education, both in Scotland and here in Canada where I moved in 1980. I returned to school in 1986 to obtain my $\mathrm{BScN}$ at the University of Toronto because I wanted to teach nursing. I'd been a preceptor for students in the intensive care setting where I worked and I really enjoyed that aspect of nursing. I found, though, that my $\mathrm{BScN}$ was just the beginning for me. My eyes were opened to the vast world of nursing in a way that I would never have thought possible. Each time I gained more education, I realized how little I actually knew and I became very humbled about what nursing has to offer - to the individual nurse, and to society as a whole. I believe that nursing can play a major role in health care across Canada but, in many ways, nursing has never lived up to its potential.

My own journey in nursing has been a long road with some interesting challenges along the way, but I would never want to give up being a nurse. Yet, I find myself frustrated at the lack of progress in nursing. I speak to students in the undergraduate program where I teach, and so many of the issues that face them today are the same ones we faced 20 to 30 years ago. How can this be and what can we do about it? I'd like to tell you a story from my initial nursing education and then one from earlier this year. I will use these stories as the background for my talk today as I lead you through some of the reasons why nursing remains relatively powerless within the health care system. I will not leave you powerless, however. Instead, I will offer some ideas for using the power and influence that are available to us, so that we, as oncology nurses, can create our own future, rather than have that future imposed upon us by others.

It was mid-1977 and I was approaching graduation from my diploma program in Glasgow, Scotland. I was almost 21 and was planning on starting my midwifery program at Guy's Hospital in London, England, the next year. I had sent off my application and expected to get in because I was one of the top students in my program. So, I was shocked when I received a letter that told me I was not accepted. All kinds of things run through your head at a time like that, but I quickly focused on the most likely reason for me not being accepted - the reference from my director of nursing was not supportive.

I had been an excellent student in class and on the wards, but I was not the 'typical' nursing student who happily stood up when a physician entered the room and gave up my seat to him. I have always had a strong sense of fairness and equality, so many of the nursing expectations did not sit well with me. I questioned the status quo and spoke up when I believed that something was wrong. The School of Nursing motto quoted by Pamela Baker at yesterday's opening, "I see and I am silent", definitely did not describe me then or now. I had complained twice in my ER rotation when, in my estimation, the lack of appropriate care led to the deaths of patients, one of whom was only 16 years of age and died from poorly treated status epilepticus. I suspected that these complaints were coming back to haunt me.

I made an appointment to speak with my director. I was scared to talk with her, but my need to ensure that justice was being done compelled me to meet her. I couldn't really believe that I was being punished for speaking up, but I had to find out. The director was very clear when I asked her outright. She had not written a good reference for me because I needed to learn a lesson. I was only a nurse, and a student one at that point. I had no right to speak up against those who were 'better' and more powerful than me physicians and more experienced nurses. As I was sure to have learned the lesson by not getting into Guy's, she would now write me the reference I deserved so I would be accepted at any other midwifery school of my choice.

Anyone who knows me knows that I did learn a lesson that day But it wasn't the one the director wanted me to learn. What I learned was that power is all around us and that some people misuse their power. I realized that I needed to identify and cultivate my power so I could be successful. But I also needed to make sure that I didn't misuse that power. Many nurses fail to recognize how power is used in health care and also fail to use their own power to their advantage. The next story illustrates how a new generation of nurses remains stuck in feeling powerless, yet we need to move forward if we are to maximize our profession's potential.

I was teaching a professionhood course this past winter to thirdyear nursing university students. Class was scheduled from 11:30 a.m. to 2:30 p.m., but students are entitled to a 10-minute break for every hour of class so we usually started at 11:30 a.m. and finished at 2:15 p.m. with a 15-minute break in the middle. Our topic for the week was oppression but, as usual, many of the students hadn't bothered to do the readings for the week, as I suspected on seeing their reactions when they entered the classroom to read the following information that I'd placed on the board: 
CHANGES TO CLASS TIMES (effective asap)

- We have so much content to cover each week that I've decided we don't have enough time for a break.

- So today, we'll work right through until the end of class.

- We will also extend the class a bit to give us more time, so we'll finish at 2:30 p.m.

- As of week seven (i.e., after Reading Week), I also expect you to be in class at 11:20 a.m., ready to start working.

- Hopefully, this will allow us to get some of the work done. If I find it's still hard to cover everything, then I'll look at the schedule again and perhaps extend the class till 2:45 p.m.

I was not really changing the schedule. Apart from anything else, I was not allowed to do so under university regulations. Instead, I wanted to use their role as students to discuss oppression in the profession. I also wanted to make the link between what I was apparently proposing and what was taken for granted in the workplace. The vast majority of the students took one look at the information on the board and left the class immediately. Many of them were upset, annoyed, even angry, yet they were unable or unwilling to face the issue of apparently having changes imposed on them by me. The students who stayed participated in an exciting and insightful debate and I e-mailed the other students to explain the intent of this teaching strategy and to give them a brief overview of what they had missed.

If you think about it, you might be able to see the parallel between what I had written for class and what happens in the clinical environment. In many settings, nurses are expected to come in 15 minutes early for report, take no breaks, and stay 30 minutes late to finish writing their notes. Why is this the status quo and what can we do to change it? These questions were the basis for some wonderful debate in the classroom and are the foundation for the rest of this talk. The good news is that we CAN change the status quo and we CAN learn how to make those changes.

\section{Context}

It is important to examine the context in which we work though, because, while individuals can make a difference once they know how to do so, they must also be aware of and work within the constraints of their environment. For example, I was a student nurse in a system that denigrated students and nurses in general. I needed to be aware of the resulting constraints so that I could learn how to work with them and around them in order to accomplish what was important to me. It would be naïve to imagine that you can learn about using your influence and power without understanding your context. However, it does not mean that the context cannot be changed as well, given the right circumstances and some effort. Context is often shaped by societal expectations that can be changed, albeit usually very slowly. Some of the main influences on our working environments that need to be taken into account and managed include the lack of clarity about what nurses' work entails, which means that we have difficulty in providing evidence about the impact of our care; escalating workload demands as patient acuity and complexity increase; a lack of control over how and when we complete our work; a frequent incongruity between the 'ideal' we strive for and the 'reality' we live, which leads to stress and anguish in many nurses; and a lack of support and resources.

\section{Gender}

Another major influence on nurses' professional lives and our ability to create our own future is gender. Gender reflects how a person lives his/her life in relation to masculinity/femininity, but it is not the same as 'sex' so it is not a genetic predisposition. Gender is socially constructed and is usually taken for granted, yet it is often poorly understood. There are cultural values attached to gender and, generally, people behave in ways that reinforce the dominant societal constructions. Indeed, many people accept the societal definitions and expectations related to gender without question, and members of a society are complicit in maintaining the 'normal' ideas. Children learn from an early age what it means to be male and female in their society and they quickly learn how they are expected to act based on their particular gender. The accepted definitions and expectations can change over time and place, however, so an examination of gender can lead to changes in what is considered 'normal' within a society (McDonald, 2003).

Gender affects nurses at both an individual and institutional level. It affects the value given to the knowledge and work we do in society and results in horizontal or occupational gender divisions where certain occupations are viewed as 'suitable' for males rather than females and vice versa. Gender also leads to vertical or hierarchical gender divisions so that 'male' occupations have higher salaries, more power, and more prestige compared with 'female' occupations. In addition, the expectation of 'woman as caregiver' in personal and familial situations has an impact on women's abilities to manage the responsibilities and time often required in 'higher' roles such as senior administration (McDonald, 2003). Is it any wonder that there is a disproportionately high number of men in nursing leadership positions (Ross-Kerr, 2002)?

Gender also makes a difference in nursing because nursing practice is equated with certain 'female' virtues, such as being caring, which has an impact on both genders. Some of the characteristics associated with femininity are submissiveness, helplessness, dependency, tenderness, nurturance, and altruism; while masculinity includes strength, aggression, mastery, independence, logic, being unemotional, competitiveness, and ambition. But are these really mutually exclusive based on gender? As a patient, would you rather have a nurse who is helpless, dependent, and nurturing or one who is strong, aggressive, and competent? As a nurse, do you see yourself as one or the other? Aren't great nurses a mixture of the best of each set of characteristics? Yet, when nursing is viewed through the lens of femininity, the significance and importance of "women's work" is diminished and our knowledge and ways of being are devalued. Further, social conditions constrain and guide the work-life choices women can make, so nursing remains a predominantly female profession with the constraints attached to being female in our society (McDonald, 2003).

\section{Oppression}

The context of our working lives in nursing has been likened to living in an oppressed society. While most nurses may not have heard this analogy, I wonder how many of you will recognize yourself, your colleagues, and/or nursing in general as I note some of the characteristics of an oppressed group. If nothing else, it might give you something to think about.

Members of oppressed groups are controlled by forces outside themselves that have greater prestige, power, and status and they are exploited by a more powerful group. Does the 'nurse-doctor' game ring a bell here? Oppressed groups internalize the norms and values of the dominant group and view them as being 'right' even at the expense of rejecting their own characteristics in an attempt to be marginal, to be more like the dominant group. As they give up their own values, they come to loathe themselves and often lash out with submissive-aggressive behaviours. Internal group conflict or horizontal violence frequently results with members attacking one another rather than the ones outside the group who are seen as being more powerful. This horizontal violence often comes from fear. Fear that the subordinate group could be destroyed if it revolted, and fear of altering the status quo because that would mean change if the revolt was successful, and people are uncomfortable with change (Roberts, 1983).

The status quo is maintained through a number of avenues. Nurses learn behaviours that are deemed acceptable by the dominant group and they fear aggression or retaliation if they 
overstep their boundaries. I guess with some reason as my experience as a student showed. Though it never stopped me from speaking out, there were negative consequences at times. But, you need to keep in mind that speaking out has also resulted in positive changes in different situations. Leadership in the oppressed group tends to reflect the culture of the dominant group, so an outspoken leader who advocates for his/her staff is not looked on kindly by the dominant group. Paradoxically, the staff may also treat the leader poorly because they do not believe that $s /$ he is really 'on their side.' Not a pleasant situation for leaders who are fighting the status quo and are doing their best for the people with whom they work.

Some leaders in powerless groups have negative attitudes towards their 'peers' as they try to associate themselves with the dominant group. Rewards, such as a promotion, may be given for 'good' behaviour and token appeasement of rights or rewards help keep the rumblings of dissatisfaction to a minimum. Myths about the dominant culture that are held by the oppressed group are encouraged and shared with new members of the profession, and education often supports the status quo by ensuring that the old beliefs are taught (Roberts, 1983). For example, the typical physician education emphasizes the role of physicians as the ultimate decision-makers in practice. Multidisciplinary education is severely lacking so health care professionals are often unaware of the skills and knowledge their colleagues can bring to clinical decision-making.

It is possible to change the status quo by becoming aware of the oppression, discarding the myths, replacing the myths with positive images of your own culture, acquiring autonomy, and leading from within to develop unity and pride among members of the group. This continuum of positive identity development (Roberts, 2000) may help you analyze where you currently lie and provide a guide for where you might want to go.

At the extreme left of the continuum is pre-encounter or unexamined acceptance where nurses accept their oppressed status, current nurses' roles, existing power structures, and physicians' power. They tend to hold a negative view of nursing at this point. I wonder how many of you have heard or even said, "I love nursing, but I'd never encourage my son or daughter to be a nurse"?

As you move through to encounter or awareness, your reality becomes altered and you recognize the injustice of the current situation. You may feel wronged and tend to see the situation as black or white, so that only nurses are correct. While you are likely to seek support from other nurses, this may result in you being isolated from other health care professionals.

Over time, immersion-emersion or connection results in increased pride and a positive identity as a nurse. This is when you are more likely to join nursing groups and share ideas from nurses about possibilities. Things look brighter for nursing.

With internalization or synthesis comes a shift to a new identity and you internalize positive views of nursing. You recognize that it's not black or white, either/or, instead you are able to see individuals and their strengths, not lump all physicians together as a group for example. Interdisciplinary relationships become important and you work at problem-solving to make a difference to nursing and to your professional life. This is when you realize that nurses are different from other health care professionals, but we are equal.

At the extreme right of the continuum is commitment and political action where you want social justice and change. You might become actively involved in social justice activities for example. In my opinion, Cathy Crowe from Toronto is an excellent example of a nurse who practises from a stance of social justice and political action.

Where are you on this continuum? Where do you want to be? And where do you think nursing fits? If you choose to move forward and make a change, how can you do it? I have two words for you: Power and Influence.

\section{Power}

Power is a word that doesn't sit well with many women. Yet it is a necessary part of life. Power describes the capacity to be influential, although it is not the same as influence, a concept that I will explore a little later. Influence is the use of power and nurses need to recognize and use their power. Authority is not the same as power. Power is involved in every human encounter and can be symmetrical or asymmetrical, though a balance of power is preferred rather than one person holding all the power. We need to accept power as positive and necessary, but do not need to grab power for its own sake. Power sharing evolves when power is centred on one's values and principles and it is this type of power that tends to come naturally to many women (Sullivan, 2004).

Principle-based power is a concept that is congruent with nursing's values. It is based on respect, honour, loyalty, and commitment. It involves understanding others and their needs/wants; keeping others informed; expressing your ideas with accuracy and enthusiasm; using your power to encourage others; respecting disagreement; and enlarging your sphere of relationships. All in all, not a bad thing and likely very positive.

\section{Types of power}

Six types of power have been identified: 1) position (authority), because of one's role; 2) information, whoever has access to information; 3) expert, whoever has the required expertise; 4) personal, because one is respected or credible; 5) connection, depends on who you know, your connection to influential others; and 6) perceived - those who have a reputation for power (Sullivan, 2004).

\section{Using power}

People with power have a responsibility to know the rules about how they should use it. You should use the least amount of power that is needed to produce the results you want and use power that is appropriate to the situation. It is also important to learn when to not use power. When using your power, focus on the problem, not the person. Make polite requests, never arrogant demands, and use coercion only when other methods don't work. Keep informed to retain your credibility when using your expert power, and understand that you may owe a return favour when you use your connection power (Sullivan, 2004).

Power that is used inappropriately is a dreadful waste. Power is misused when it is not matched to the situation. People who under-use power, i.e., don't use it when it is needed, lose their credibility and are often perceived as incompetent. Those who overuse their power and over-react to a situation end up with problems as well. Their overuse of power sows fear and hostility in others and stifles creativity and problem-solving. It often leads to a lack of trust and a diminished ability for the person to achieve his/her goals. Power is lost when you continually make poor decisions or fail to make decisions (Sullivan, 2004).

\section{Recognizing your own power}

You likely recognize the types of power and could identify people who have power and either use it well or misuse it in some way. But do you recognize your own power? Do you value your power and realize what happens when you don't use it? People who don't use their power may miss opportunities for themselves, their patients, and their profession. They may appear indecisive or be perceived as less able than they actually are. They risk diminishing their credibility, and thus their future effectiveness will be reduced. Finally, their opinion may be dismissed and they may be overlooked in many situations (Sullivan, 2004).

CANO members were offered an opportunity in this twentieth anniversary year to use their power by sharing stories about the 
difference they made in people's lives because they are oncology nurses. This was a chance to showcase what we do as oncology nurses and to 'blow our own horns' a bit. Unfortunately, not a single response was received for the journal. Imagine how powerful it would have been to be able to share those stories with other health care professionals or even simply with each other. A missed opportunity indeed.

\section{Increasing your power}

I hope by now you are starting to think that perhaps having power is not such a bad thing and, in fact, it might even be to your benefit to be powerful. So, how can you increase your power within an organization so you can change the status quo and begin to take charge of your own future? One way is to improve your visibility in the organization. Increase your level of involvement, make sure that you do your job with efficiency and effectiveness, and take on extra responsibilities as you are able. Learn all you can about the organization and the people in it. Don't be afraid to ask for help and advice, and continue to develop yourself and your skills. Lifelong learning should be a strong goal in your professional life. Take a stance when decisions need to be made. Don't be a sheep and simply follow others. Instead, give your opinion after careful consideration of the facts. Weigh up the pros and cons. Embrace change and look for the positives, do not simply sit back and criticize. I don't mean you should accept change just for change's sake, but I do know that many changes have great potential. Yet they are defeated by unwilling participants who don't necessarily hate the idea, they just don't want to deal with change. Remember to network within the organization and in as many other places as you can. Make sure you associate with the power players as appropriate. Finally, share your power with others; it will come back to you twofold (Sullivan, 2004).

\section{Undermining your power}

We are all capable of being powerful. Yet, many of us undermine our own power (or that of others) without necessarily realizing what we are doing. Our human fear of change holds us back. The thought of making changes or having to live through them scares us, so we find ways of preventing change from occurring. Yet, if we do not embrace change, then how can we expect to make a difference in our professional lives? One of my favourite nonmedical definitions fits nicely in here. Do any of you know what the definition of insanity is? It's doing the same behaviour over and over again, yet expecting a different outcome. How true. Can you explain to me why we should expect anything to change and improve if we don't alter our behaviour and initiate a new outcome?

I'm sure some of you will recognize yourself or colleagues in the following behaviours that undermine power. Please don't be embarrassed or upset if you do. Instead, decide to accept your power and work on increasing it while striving to eliminate the behaviours that undermine power. One of my least favourite behaviours and not one that I can usually be accused of is griping. You know, when you make comments about something or someone, but don't say it to the person's face? When you talk about your administrator behind her back, for example, instead of voicing your concerns in a way that allows for open discussion and a possible solution. Another behaviour is whining, which accomplishes nothing and can give you a bad reputation. Rather than making excuses for not trying something, you need to solve problems by exploring alternative solutions. Be prepared to take a risk, even if you fail. Then there are the killer phrases. We can't do that because... 'She'll get mad; They'll think I'm showing off; It'll cost too much; We tried that before; Admin. won't go for it' and so on. Recognize them? How often have you used them? Don't be negative. You need to find solutions and ways of making something work if it has potential (Sullivan, 2004).

The final two behaviours can be very difficult to manage, but it's worthwhile working on them. It is too easy to have an emotional reaction to someone's suggestion, but reacting emotionally tends to be self-defeating. You need to learn that what happens in the work environment is about work and you shouldn't take it personally, though women often have a hard time with this. Take some time out to recover your equilibrium and then discuss the issue in a more professional, rational manner. Remember that ideas can be debated and even attacked, but a person should never be attacked. Finally, too many people refuse to admit their mistakes, which leads to a loss of power. You need to take responsibility for a mistake and offer to fix it. But then you need to move on. Don't berate yourself over mistakes. Learn to discriminate between minor and major mistakes and deal with them accordingly (Sullivan, 2004). Remember that many of life's discoveries occurred because of mistakes.

\section{Moving forward to create our own future as oncology nurses}

So far, we have explored some barriers that affect our ability to create our own future as oncology nurses and we have learned about the importance of power and how to increase our power. Now we need to explore how we can use our power to effect change and to take charge of our own destinies. I will use three areas, using influence, becoming a leader, and joining professional organizations, to illustrate my belief that we do have the power, if only we use it!

\section{Influence}

There are close to a quarter of a million RNs practising in Canada and we account for almost half of the health care workers in our system (Building the future, 2004). Imagine how influential we could be if we learned how to harness and use our power? So, what is influence?

Influence is the ability to communicate your ideas to others and to gain their support through acceptance or participation. It can exist only in relationships with others, and is related to a specified goal within the context of your own life and work. Influence is more important than authority and is affected by everything about you, both personally and professionally. Influence may be bestowed or earned, broad or limited. Influential skills can be taught and learned, but the ability to be influential is affected by past events (Sullivan, 2004). Before examining how you as an individual can become influential, it is important to go back to context and describe the three main historical factors that have influenced present-day nursing so you have a sense of why nursing as a profession has struggled to be influential.

\section{Historical influences on nursing}

Florence Nightingale was nursing's first person of influence. If you remember your history, you will recognize that nursing has a strong military history since Florence's work in the Crimean War. The military requires discipline, adherence to orders, and respect for the chain of command, so those characteristics were adopted into nursing as well. We also have a strong religious history as the first hospitals and schools of nursing were begun by religious orders to provide care to the poor. Religious orders valued service and obedience. Finally, we've already touched a little on our women's history where nursing is viewed as a female profession and women's work is undervalued (Sullivan, 2004).

\section{Other barriers to nursing's influence}

Other barriers to nursing's influence in modern society include external demands such as the funding structure of the health care system that reduces nurses' influence, the fact that nurses have little say as employees, the traditional power and prestige of physicians (who are not usually employees), and the public's inaccurate perception of nursing. Internal barriers include our nursing culture and oppressed behaviours, as well as our tendency to diminish our 
own accomplishments (Sullivan, 2004). All of these factors constrain nursing's ability to be influential, but none of them are insurmountable barriers if we actively choose to become the influential profession we say we want to be.

\section{Individual influence}

Having explored some of the barriers to nursing being influential, you might be asking why you as an individual should want to be influential. Well, influence is not about achieving success just for oneself and one's own gain. Influence could be used to improve patient care, achieve better working conditions, or improve the health of your fellow citizens for example. You have many opportunities to use influence and it's a shame to waste an opportunity. You can be influential at the bedside; during formal and informal meetings at work; on committees; in casual conversations; in the community at professional meetings; in volunteer groups, and so on. The possibilities are almost endless (Sullivan, 2004).

\section{The game}

One of the main reasons for becoming influential as an individual is that even though women tend not to want to hear this, work is a game. Like it or not, nursing (work) is a game and games are played by rules which you need to learn and use in order to thrive and survive. Work is about success, and is different from social life which is about pleasure and approval. Thriving means success on the job and the ability to accomplish one's goals. In everyday life, women often 'win the game' by feeling good about what they do. However, nurses tend not to measure success in these terms, but instead relate success to being rewarded with money, gratitude, and respect - all of which are in short supply too often. Are there perhaps some other reasonable goals and successes in nursing that we could start to use instead? Successes that mean something to us as individuals? For example, what if success was measured by your ability to care for patients, teach students, or manage a unit or department? Or by how good you feel about your work, how much you are learning, how you are developing relationships with colleagues to get your work done, or how many contacts you are making to help you in the future (Sullivan, 2004). Would you then feel more successful in this game of nursing? It's something to think about.

Games have rules for playing and winning, but one of the difficulties in playing this game is that the rules are not written down anywhere, yet you need to be aware of them (and play by them) in order to thrive. The rules include learning to barter or exchange favours; recognizing quid pro quo, which are the currency/chips of bartering; using the grapevine because information is the most valuable currency; using non-confrontational tactics; using leverage; accepting that you might need to lose the battle to win the war; making connections; accepting responsibility; becoming a team player; cultivating loyalty; seeking mentors; and accepting risk (Sullivan, 2004).

Now I can almost hear some of you bristling. Why should you use the rules? Why can't you just do what you want? Well, there are a number of reasons and not using the rules can certainly be to your disadvantage. It is important to realize that organizations operate within the rules, that line positions have clout, and that you need authority to assume responsibility. Status symbols are important, despite what you might think. Who gets to park where or what group gets to close the clinics because their national conference is on reflect status which, in turn, reflects the rules by which the game is played. Using the rules means that you can perhaps influence the organizational culture. Using the rules can be to your advantage; not knowing them leaves you in the dark.

I certainly do not advocate following the rules unquestioningly. There will be times when they need to be violated, but you need to understand when, where, and how to violate them after a careful evaluation of the pros and cons. Sometimes, it really is better to ask forgiveness than permission. But, there are some rules you should never break - never badmouth your boss, never avoid paying a debt, never sabotage a team, and never, ever lie. They will all have negative consequences (Sullivan, 2004).

While the rules are there, nursing doesn't fit the rules very well for three reasons. One, we are a predominantly female profession and the rules were developed by men. Two, we are an inherently 'feel-good' profession and the idea of planning your career so you are successful rather than just taking the kudos as they appear doesn't come naturally to many of us. And three, nursing has its own rules: no one nurse is more important than another; everyone should stay on the same level; don't brag; give credit to others; and include everyone. Sound familiar? But where does that leave us? Are we ever going to move forward as an individual and a profession if we don't tell people what we do and take credit for doing it well?

Even though the rules might not be the best fit, you can make them work for you. Stop being a victim and 'deliver the mail to the right person' - in other words, don't keep complaining to your colleagues, go to the person who has the authority to make a change (Sullivan, 2004). Speak up for yourself, your patients, and your profession. Don't assume responsibility without authority. Don't do the dirty work alone. Accept the risk. Learn when to violate the rules. And extremely important, care for yourself - not something we are good at doing as nurses, yet as Judy Atkinson reminded us in her Circles of Rhythm experiential presentation, we have to be healthy ourselves or we cannot fully care for others.

\section{Optimizing your capacity for influence}

If you do choose to become influential, then there are some steps you need to take to optimize your capacity for influence. How we present ourselves is an outward expression of our inner experience, so you need to assess the ways in which you present yourself. Selfpresentation includes subtle and not-so-subtle behaviours along with appearance, and originates from the attitude you hold about yourself. You need to evaluate your current ability to be influential and this self-awareness can occur through introspection and from formal and informal feedback from others. You also need to assess your own skills of influence in an ongoing way so you can evaluate how effective certain strategies are with individuals and groups. Becoming influential is a process that enhances your ability to listen to others by developing your perceptive skills. It can improve your ability to be effective in meeting your goals and those of nursing (Sullivan, 2004). It does come with risks of course, such as inspiring envy or jealousy in others. But don't let that hold you back!

\section{Become a leader}

Now that you understand how power and influence work, you need to put your knowledge into practice by being a leader. One of CANO's value statements is that 'Every nurse is a leader'. We all have the capacity to be leaders in some aspect of our lives, to envision the future and, as Toben challenged us, to achieve our dreams and become our own heroes. A leader does not have to hold a specific title or authoritarian position, nor are leaders only born; they can also be made or developed. The inherent qualities within an individual can be supplemented by leadership skills you learn in your professional education and throughout your career. Nurses can be leaders at the bedside, in management, in the community, in academia, etc. The only limits are those imposed by ourselves. Leadership requires innovation and the ability to make changes. Although change can be very uncomfortable for people, it is an essential part of our daily personal and professional lives (Tamlyn \& Reilly, 2003).

What are some of the attributes of nursing leaders? A nursing leader needs vision and the ability to translate that vision into action. $\mathrm{S} /$ he must also be knowledgeable about the nature of change in the larger society as well as in health care. A leader must have the confidence to challenge the status quo and promote alternate solutions 
- even if they are unpopular solutions at the time. A leader must also be visible so that his/her work is recognized and listened to.

Leadership requires four main qualities, the four As: awareness, assertiveness, accountability, and advocacy. As a leader, you need to be aware of yourself and your personal characteristics. What is your level of maturity, i.e., your willingness and ability to do a task? How motivated are you? You need to want to be a leader and be able to accept responsibility for your own actions as well as those of the group. Your ability to be a leader is related to the knowledge level or base you have in an area, so you need to be knowledgeable in the appropriate spheres. You must be able to think clearly and strategically, and understand and articulate your goals. Be aware of power, and how it is achieved and used, so you do not misuse it. Know your own personality and how you are viewed by others; e.g., the extent of your own self-confidence, enthusiasm, flexibility, creativity, honesty, sincerity, tact, and friendliness. Personal appearance is also important as leaders must be 'presentable.' Your old jogging suit doesn't cut it when you're trying to be taken seriously. You need to have good interpersonal relationships, so communication skills are vital. Endurance is also needed because of stressful demands. It helps to have a personal plan for stress management and you need to learn when it is appropriate to say no and to do so - remember that "No" is a full sentence! When asked to take on something you really don't have time to do, stop saying, "No I can't, but....", "No, I can't, but if you don't find someone else then I'll do it." You know what happens then! You need to know how you deal with success and failure and how to be graceful in each for failure is highly likely when you take the risks that a good leader must take. Paul Brandt reminded us on Sunday that while you won't fail if you don't try, if you don't try, then you are not living life to its fullest. Finally, you must be able to assess the strengths and limitations of each group member and use that knowledge appropriately, plus assist people to work towards overcoming their limitations, working towards their potential, and being a productive member of the group (Sullivan, 2004). Exhausted yet? Well don't give up. It is worth it!

A good leader should be assertive, not aggressive. Nonassertive people tend to put themselves down and let others make choices and decisions for them, often to avoid conflict, but they usually end up angry with themselves and with others. Aggressive people are similar to assertive ones in their goal, however they do it by ignoring the rights of others and often at the expense of others. Successful leaders know how to express their feelings, needs, and ideas, and stand up for their own rights while considering the rights of others. They maintain their own integrity as well as that of the other. Assertive people establish close relationships, protect themselves from being used by others, make their own life decisions and choices, identify and meet many of their interpersonal needs, and express positive and negative feelings both verbally and non-verbally (Bernhard \& Walsh, 1990). Assertive people usually feel good about themselves and others. Why wouldn't you want to be an assertive person? How could being assertive help you create your own future as an oncology nurse? Think about it.

The third quality of a good leader is that of accountability. Thus, you are answerable for the negative or positive outcomes of your actions. The buck stops with you. Your accountability is threefold: 1) first, you are accountable to yourself, so you always need to do your personal best; 2) second, you are accountable to others, including admitting failures and not making excuses for yourself; and 3) third you are accountable to your profession which means meeting professional standards in your own practice, as well as being willing to judge your peers and to develop your own ability to make those judgments.

Advocacy is the final quality that is important in a good leader. Leaders who value advocacy support, defend, and maintain the cause of someone or something. They assist an individual or group to achieve and use power effectively to produce certain desired changes
(Bernhard \& Walsh, 1990). A leader who is your advocate is a treasure you need to recognize and value. Being a leader will help you shape your future and that of your profession.

\section{Join your professional organization}

The final point I want to make is the role of professional organizations. As I said before, there are close to 250,000 RNs in Canada and we account for almost half the health care workers in the country (Building the future, 2004). Nurses are the health care practitioners most respected by the public, yet we do not have a clear voice in health care. What if we were to work together - could we make a difference? I believe that an effective way of optimizing influence and power is through professional organizations, such as CANO, which have the potential to speak for their members. There is power in numbers and remember, power means influence.

Although we have no clear statistics on how many nurses work in oncology throughout Canada, I suspect that many of those 250,000 RNs in our country work with oncology patients on a regular basis. Imagine the power and influence CANO would have if we could truly speak for thousands of nurses? Yet, there are only about 900 members in CANO this year - much better than most other nursing specialties, but far less than the potential. Recent statistics (Canadian Nurses Association, 2004) show that in 2004 slightly more than 1,200 nurses are certified or recertified through the Canadian Nurses Association as CON(C), Certified Oncology Nurses in Canada - oncology nurses who have gone that extra mile to lay claim to their specialized knowledge. Nurses who have the demonstrated knowledge, status, language etc., to talk with team members at a professional level.

Many of the $\mathrm{CON}(\mathrm{C})$ nurses are not members of CANO, however, and you have to wonder why not? How can we invite those nurses into CANO and how can we increase our overall membership significantly, given the large numbers of nurses who work in oncology, so we can increase our influence and create our own future? You'll be pleased to hear that the CANO Board of Directors is working diligently to answer these questions. But in the meantime, I would ask you to think about what you can do yourself - some of you in this room are not CANO members yet, but membership information is available, just ask at the registration desk! Some of you work with colleagues who are not CANO members. How can you encourage others to become active members of CANO so we speak as one strong voice to direct our specialty's growth and scope of practice? There are many possibilities, from reducing barriers to membership to requiring nurses in oncology settings to be members of CANO. I believe that, as professionals, we have an obligation to contribute to our profession in whatever way we can. Participating in your professional organization is one way of enhancing your own professional life as well. Imagine what would happen if every CANO member recruited just one other member for 2005? How much further could our power and influence spread? How much easier would it be for us to take charge and create our own future?

\section{Conclusion}

I'd like to bring us full circle now as I draw to a close and once again ask the question, "Do we have the power to create our own future as oncology nurses?" My answer would be 'Yes' we have the power. However, it comes with a caveat. We have the power, but we don't always know the extent of our power or how to use it to our advantage. My goal today was to increase your awareness about the possibilities that lie ahead. To start you thinking about how we can use our power and be influential in directing oncology nursing. My hope is that you learned something today that you can take away and use in your practice to: challenge the status quo, initiate the changes that are needed, and create your own future as an oncology nurse. Thank you.
CONJ • 15/1/05
RCSIO • 15/1/05 


\section{References}

Bernhard, L., \& Walsh, M. (1990). Leadership: The key to the professionalization of nursing ( 2 nd ed.). Philadelphia, PA: The C.V. Mosby Company.

Construire l'avenir : une stratégie intégrée pour les ressources humaines infirmières au Canada (2004). Soins infirmiers au Canada. Consulté le 20 sept. 2004 à l'adresse :

http://www.buildingthefuture.ca/f/nursing/

Canadian Nurses Association. (2004, June). Section 1 - Update report from the CNA certification program. Ottawa: Author.

McDonald, C. (2003). Issues of gender and power: The significance attributed to nurses' work. In M. McIntyre \& E. Thomlinson (Eds.), Realities of Canadian nursing: Professional, practice, and power issues (pp. 357-371). New York: Lippincott Williams \& Wilkins.
Roberts, S. (1983). Oppressed group behaviour: Implications for nursing. Advances in Nursing Science, July, 21-30.

Roberts, S. (2000). Development of a positive professional identity: Liberating oneself from the oppressor within. Advances in Nursing Science, 22(4), 71-82.

Ross-Kerr, J. (2002). Gender issues in nursing. In J. Ross-Kerr \& M. Wood (Eds.), Canadian nursing: Issues and perspectives (pp. 83-99). New York: C.V. Mosby Company.

Sullivan, E. (2004). Becoming influential: A guide for nurses. Upper Saddle River, NJ: Pearson Education.

Tamlyn, D., \& Reilly, S. (2003). Innovation and contemporary nursing leadership. In M. McIntyre \& E. Thomlinson (Eds.), Realities of Canadian nursing: Professional, practice, and power issues (pp. 494-515). New York: Lippincott Williams \& Wilkins. 